\title{
FINANSIëLE ASPEKTE VAN GEMEENTES VAN DIE GEREFORMEERDE KERKE IN SUID-AFRIKA: 'N EMPIRIESE ONDERSOEK
}

\author{
D.S. Lubbe en J. Lubbe \\ Departement Rekeningkunde \\ Universiteit van die Oranje-Vrystaat \\ BLOEMFONTEIN
}

\begin{abstract}
As a result of the presbyterial system of church govemment of the Refomed Church in South Africa (Gereformeerde Kerke in Suid-Afrika), very little information on the financial matters of the church is available. Hardly any research has been undertaken on the financial matters of congregations of the said church. The aim with this research was firstly to obtain the opinions of clergymen and cashiers within the ranks of the Reformed Church on certain aspects of the financial matters of their congregations and the church as a whole. Secondly certain data from which guidelines on the financial matters of congregations can be drawn, were collected and processed. From the research it became clear that there is a great need for financial guidelines in respect of financial planning and management in congregations and that church finances offers a vast field of study for future research.
\end{abstract}

\section{INLEIDING}

Die kerkregeringstelsel van die Gereformeerde Kerke in Suid-Afrika (GKSA) is gegrond op die presbiteriale (gereformeerde) benadering waarvolgens die plaaslike gemeente (of kerk) beskou word as 'n selfstandige, sigbare openbaring van die liggaam van Christus (kyk Kerkorde, 1979:12). Volgens genoemde stelsel van kerkregering word 'n gemeente regeer deur die kerkraad en meerdere vergaderings is vergaderings van plaaslike kerke wat slegs handel met daardie sake wat nie in mindere vergaderings afgehandel kon word nie of wat die belang van die kerke gesamentlik raak (kyk Kerkorde, 1979:12,13).

In die lig van bogenuemde kerkregeringstelsel word 'n plaaslike gemeente se tınansiële angeleenthede deur die betrokke kerkraad beheer. Volgens hierdie stelsel doen ' $n$ gemeente nie oor sy finansiële stand van sake verslag aan 'n meerdere vergadering nie. Dit bring mee dat daar buite gemeenteverband baie min inligting bekend is oor die finansiële aangeleenthede van die Gereformeerde Kerke. Daar is skynbaar ook baie min indien enige wetenskaplike navorsing onderneem oor die finansiële sake van gemeentes van genoemde kerk. By kerke waar die regeringstelsel meer neig na 'n kol- 
legialistiese stelsel (waarvolgens die plaaslike kerkraad ondergeskik is aan 'n sinodale genootskapsorganisasie en mindere vergaderings uitvoerders van sinodale gesag is (kyk Kerkorde, 1979:11), is daar gewoonlik 'n sentrale punt soos 'n 'kerkkantoor' of raad vir finansies waaraan die gemeentes verslag moet doen oor hul finansiële sake. So 'n raad vir finansies lè ook in hierdie gevalle gewoonlik sekere finansiële riglyne neer wat deur plaaslike gemeentes nagevolg moet word.

Dit is nie die doel met hierdie artikel om betrokke te raak by teologiese argumente ten gunste van of teen 'n bepaalde kerkregeringstelsel nie. So jets sou in elk geval buite die opleidingsveld van die skrywers val. Die feit dat finansiële riglyne soos dié waarna hierbo verwys is nie in die Gereformeerde Kerke bestaan nie, asook die merk wat die verswakkende landsekonomie en hoë inflasiekoers op baie gemeentes se finansiële toestand laat, was die beweegrede om hierdie navorsing te onderneem.

Berigte oor proponente wat nie beroepe kry nie, gemeentes wat die moontlikheid van tentmakerbediening ondersoek, die invloed wat die ontvolking van die platteland op dié gemeentes het, die feit dat die afstigting van nuwe gemeentes feitlik tot stilstand gekom het en gemeentes wat nie hulle finansiële verpligtinge kan nakom nie, verskyn gereeld in die pers. Die Gereformeerde Kerke kan nie hulle oë sluit vir hierdie probleme nie, want baie gemeentes ondervind van hierdie probleme aan eie lyf. Profetiese woorde soos dié van Boshoff $(1990: 5,6)$ kan nie geïgnoreer word nie. Hy wys daarop dat die realiteit sal moet deurdring dat "die era van maar net stygende inkomste iets is wat in die negentigerjare verby is ... (g)emeentes sal al meer sy aktiwiteite moet beplan in die lig van bekostigbaarheid en nie in terme van die ideale nie ... gemeentes sal net al meer en meer die styl van bekostigbaarheid moet begin aankweek". (Vergelyk ook navorsingsbevindings in die V.S.A. van Cunningham \& Reemsnyder, 1983:58-62.)

Die doel met die navorsing was eerstens om die menings van predikante en kassiere binne die geledere van die Gereformeerde Kerke te verkry oor sekere aspekte van die finansiële sake van hul gemeentes en van die Kerk in die breë. Tweedens is sekere inligting waaruit riglyne oor die finansiële aangeleenthede van gemeentes getrek kan word, ingesamel en verwerk.

\section{NAVORSINGSMETODIEK}

'n Steekproef van dertig gemeentes is met behulp van ewekansige tabelle (Arens \& Loebbecke, 1981:36) getrek uit die lys van gemeentes soos vervat in die Almanak van die Gereformeerde Kerke in Suid-Afrika $(1991: 8,9)$. Twee verskillende vraelyste is opgestel en aan die dertig gemeentes gestuur. Die een vraelys is gerig aan die 
predikant en die ander aan die kassier van die gemeente. In gevalle waar 'n gemeente oor die dienste van meer as een predikant beskik, is 'n vraelys aan elkeen van die predikante gestuur.

Die vrae aan die predikante en kassiere kan in die volgende drie kategorieë verdeel word:

- Die vergoeding van en sekere diensvoorwaardes vir persone in diens van die gemeente.

- Die bydraes van lidmate.

- Finansiële beheer en rekordhouding in en finansiële verslagdoening deur gemeentes.

\section{TERUGVOERING}

Twintig gemeentes $(66,6 \%)$ se vraelyste is terugontvang. Twee gemeentes se vraelyste kon egter nie gebruik word nie, wat meegebring het dat daar met 'n responskoers van $60,0 \%$ gewerk is. Vraelyste bevat inligting van gemeentes vir die tweede kwartaal van 1991.

Die geografiese verdeling van die respondente was soos volg:

$\begin{array}{ll}\text { Stad } & -38 \% \\ \text { Grootdorp } & -17 \% \\ \text { Platteland } & -45 \%\end{array}$

\section{RESULTAAT VAN ONDERSOEK}

\subsection{Traktement, vergoeding en ander voordele}

\subsubsection{Die predikant}

Artikel 11 van die Kerkorde van die Gereformeerde Kerke in Suid-Afrika (1979:16) bepaal soos volg: "Die kerkraad wat die kerk verteenwoordig, is verplig om sy bedienaar van die Woord met behoorlike onderhoud te versorg." Voorafgaande benadering strook met die presbiteriale kerkregeringstelsel waarna reeds verwys is. In die praktyk is die bepaling van die traktement van 'n predikant egter dikwels 'n netelige en omstrede aangeleentheid weens die feit dat 'n kerkraad meestal geen riglyn in dié verband het om as maatstaf te gebruik nie. (Vergelyk ook byvoorbeeld Spoelstra, 
1989:89-91 en Van der Walt, 1972.) Oor die jare was daar al baie meningsverskille oor die toepaslike prosedure om 'n predikant se traktement te bepaal en die vraag of meerdere vergaderings nie moontlik riglyne in dié verband moet verskaf nie. Uit die vraelyste het dit geblyk dat daar tans ten minste een klassis is wat wel riglyne oor die traktement daargestel het.

Dit blyk egter dat in die afwesigheid van riglyne deur meerdere vergaderings heelwat gemeentes hulle predikant se traktement koppel aan 'n salarisskaal van 'n sekulêre beroep soos byvoorbeeld dié van 'n senior lektor aan 'n universiteit. Van die respondente het $22 \%$ angedui dat hul predikante se traktement aan sodanige skale gekoppel word. Van die predikante wie se traktement nie aan sulke skale gekoppel is nie, het $50 \%$ aangedui dat hulle dit sou verkies het indien hulle traktement wel aan sodanige skaal gekoppel sou word. Dieselfde vraag is aan kassiere gestel en van hulle het $16 \%$ gemeld dat hulle dit sou verkies dat die predikant se traktement aan so 'n skaal gekoppel word. Dit was duidelik uit sommige van die 'oop' vrae dat 'n hele aantal van die predikante en kassiere wat gemeld het dat hulle nie vaste skale vir die traktement voorgestaan het nie, hulle antwoorde nie op beginselbesware grond nie, maar op die praktiese oorweging dat hulle gemeentes se finansies te swak is om hierdie, volgens hul mening, 'hoër' traktement by te bring.

Uit die antwoorde blyk dit dat die traktement van predikante wissel tussen R2180 en R5750 per maand, met 'n gemiddelde van R3400 per maand. 'n Wesenlike deel van die respondente $(88 \%)$ ontvang ' $n$ jaarlikse bonus wat gelyk is aan een maand se traktement. Die oorblywende $12 \%$ van die respondente ontvang 'n jaarlikse bonus gelykstaande aan $70 \%$ van 'n maandelikse traktement.

Van die respondente is $89 \%$ woonagtig in 'n pastorie wat deur die gemeente verskaf word, terwyl $11 \%$ in hul eie huis woon. Van die predikante wat in 'n pastorie woon, het $81 \%$ aangedui dat hulle dit sou verkies om in hulle eie huis te woon. Die predikante wat in hul eie huis woon, het almal aangedui dat hulle dit verkies om nie in 'n pastorie van die gemeente te woon nie. Die behuisingstoelae aan predikante wat hul eie huis bewoon, wissel van $R 930$ tot $R 1275$ per maand, met 'n gemiddelde toelae van R1068 per maand.

Van die respondente stel $33 \%$ 'n motorvoertuig tot beskikking van die predikant, terwyl $67 \%$ 'n reistoelaag betaal. Weens geografiese verskille tussen gemeentes kon geen wetenskaplike afleidings uit die reiskoste wat betaal word, gemaak word nie, behalwe dat by $90 \%$ van die gemeentes wat wel so' $n$ toelaag betaal, dit in die vorm van 'n vaste maandelikse bedrag is, terwyl $10 \%$ hul predikant vergoed op 'n basis van afstand gereis in diens van die gemeente. 


\subsection{Die koster}

Van die respondente het $24 \%$ aangetoon dat, veral weens die ekonomiese probleme, hul koster(es) geen vergoeding ontvang nie. Die vergoeding van kosters by die oorblywende $76 \%$ van die respondente wissel tussen R25 en R460 per maand, met 'n gemiddelde bedrag van $R 230$ per maand. Die meeste kosters wat 'n vergoeding van meer as R290 per maand ontvang, moet egter self uit hul 'vergoeding' items soos skoonmaakmiddels aankoop en enkele kosters betaal ook uit hierdie bedrag ' $n$ bediende wat met die skoonmaak van die kerkgebou help.

Slegs $15 \%$ van die respondente wie se kosters vergoeding ontvang, betaal ook 'n jaarlikse bonus aan hulle en in al hierdie gevalle is dit gelykstaande aan een maand se vergoeding.

\subsubsection{Die sekgetaresse/administratiewe beampte}

Slegs $24 \%$ van die respondente het aangetoon dat hulle oor die dienste van 'n sekretaresse/administratiewe beampte beskik. Die meeste gemeentes wat nie oor die dienste van so 'n persoon beskik nie, het aangedui dat hierdie funksies gesamentlik verrig word deur die skriba, die kassier, 'n vrywillige tikster en die predikant.

By gemeentes wat wel oor die dienste van 'n sekretaresse beskik, wissel die vergoeding tussen R190 en R600 per maand, met 'n gemiddelde maandelikse vergoeding van R375. Slegs $25 \%$ van die sekretaresses ontvang 'n jaarlikse bonus. Dié bonus is gelykstaande aan $90 \%$ van 'n maand se vergoeding.

\subsubsection{Die orrelis}

Van die respondente is daar $12 \%$ wat geen vergoeding aan hul orrelis(te) betaal nie. Die meeste van dié respondente het aangedui dat hulle orrelis(te) hierdie diens gratis verrig in die lig van die gemeente se swak finansiële toestand.

In gevalle waar die orrelis(te) wel vergoed word vir hulle dienste, wissel die bedrag tussen $R 60$ en $R 460$ per maand, met 'n gemiddelde vergoeding van $R 198$ per maand.

\section{Bydraes van lidmate}

Van die respondente het $83 \%$ aangetoon dat hul lidmate self hul bydraes deur middel 
Finansiële aspekte van gemeentes van die Gereformeerde Kerke: 'n empiniese ondersoek

van bydraekoeverte inbring, terwyl by $17 \%$ van die respondente, die ampsdraers die bydraes by lidmate afhaal. Dit blyk dat slegs 'n klein persentasie lidmate per aftrekorder bydra.

Die vraag is aan predikante gestel watter wyse van inbring van bydraes deur lidmate volgens hulle oordeel die beste werk en $72 \%$ het aangedui dat hulle bydraekoeverte verkies, $16 \%$ dat ampsdraers bydraes afhaal terwyl $12 \%$ angedui het dat hulle aftrekorders verkies. Uit eersgenoemde groep het 'n hele paar aangedui dat hulle inderdaad sou verkies dat ampsdraers bydraes moet afhaal, maar dat dit nie prakties moontlik is nie weens ampsdraers se gebrek aan tyd.

\subsection{Finansiële beheer, rekordhouding en verslagdoening}

Al die respondente het aangedui dat hulle gemeente oor 'n finansiēle komitee beskik. Die aantal lede waaruit die komitee bestaan, het gewissel van 3 tot 9 lede, met 'n gemiddelde ledetal van 5 (benaderd). Op die vraag hoe gereeld hierdie komitee vergader, is die volgende antwoorde verkry:

$\begin{array}{ll}\text { Maandeliks } & 35 \% \\ \text { Kwartaalliks } & 41 \% \\ \text { Sesmaandeliks } & 24 \%\end{array}$

By $24 \%$ van die respondente het die kassier ook opgetree as voorsitter van die fimansiële komitee. Predikante was by $47 \%$ van die respondente lid van die finansiële komitee. Op 'n vraag aan predikante of hulle van mening is dat 'n predikant lid behoort te wees van 'n gemeente se finansiële komitee, het $44 \%$ 'ja' geantwoord en $56 \%$ 'nee'. Van laasgenoemde groep het 'n paar baie sterk standpunt ingeneem dat ' $n$ predikant veral nie kennis moet dra van die bydraes van individuele lidmate nie.

Al die respondente het aangedui dat hulle wel verslag doen aan die kerkraad oor die gemeente se finansies. Die gereeldheid waarmee daar verslag gedoen word, is soos volg:

$\begin{array}{ll}\text { Elke maand } & 53 \% \\ \text { Elke twee maande } & 6 \% \\ \text { Kwartaalliks } & 41 \%\end{array}$

Slegs $18 \%$ van die respondente het aangedui dat daar nooit aan die gemeente in vergadering of andersins verslag gedoen word oor die gemeente se finansies nie. In die meeste gevalle $(71 \%)$ waar daar wel só verslag gedoen word, word dit gedoen by wyse 
van gemeentevergaderings. In $21 \%$ van die gevalle word verslag aan die gemeente gedoen deur middel van 'n berig in 'n gemeentenuusbrief, terwyl $8 \%$ van die respondente aangedui het dat ouderlinge tydens huisbesoek gesprek voer oor die gemeente se finansies. Respondente by wie wel verslag aan die gemeente gedoen word, het soos volg gereageer op die vraag hoe gereeld dit geskied:

$\begin{array}{ll}\text { Elke twee maande } & 7 \% \\ \text { Kwartaalliks } & 14 \% \\ \text { Sesmaandeliks } & 7 \% \\ \text { Jaarliks } & 72 \%\end{array}$

Vir ondernemings, klubs, ensovoorts in die sekulêre gemeenskap dui die bestaan van 'n finansiële en interne beheerhandleiding gewoonlik teoreties op goeie finansiële beheer. Sodanige handleiding lê onder andere riglyne neer vir die ontvangs van geld, die deponering van geld en rekeningkundige en verslagdoeningsprosedures wat gevolg moet word. By 'n instansie soos 'n klub waar tesouriers gereeld wissel, waar baie lede dalk nie oor finansiële kundigheid beskik nie en waar goeie interne beheermaatreëls om verskeie redes nie moontlik is nie, is 'n handleiding soos dié waarna hierbo verwys is, 'n noodsaaklikheid. Die kerk wil geensins gelykgestel word aan 'n sekulêre instelling soos 'n klub nie, maar die uitvoering van rentmeesterskap oor fondse deur byvoorbeeld ' $n$ kerk, 'n klub en 'n liefdadigheidsinstelling is nie verskillend van aard nie. Lubbe $(1987: 34,35)$ wys tereg daarop dat

kerke en klubs ... nie immuum (is) teen bedrog nie maar sodanige organisasies is om verskeie redes dikwels ongeneë om regstappe in geval van bedrog in te stel. Baie gevalle van bedrog kom dus nooit onder dic publick se aandag nie ... Daar is talle voorbeelde van die eerbare en voorbeeldige ouderling of diaken en die lojale en hardwerkende tesourier wat tot almal se verbasing bedrog geplecg het. (Vergelyk ook Boyce, 1984:96 en Armacost \& Schneider 1989:41.)

Slegs $6 \%$ van die respondente het aangedui dat hul gemeentes wel oor 'n handleiding soos hierbo genoem beskik. Op 'n vraag of daar 'n behoefte bestaan aan 'n handleiding wat as riglyn kan dien vir gemeentes het $53 \%$ van die kassiere aangedui dat daar wel so ' $n$ behoefte bestaan. Dit was egter interessant om daarop te let dat dit veral kassiere met naskoolse opleiding in rekeningkunde is wat aangedui het dat hulle nie 'n behoefte ervaar aan sodanige handleiding nie. Van al die kassiere beskik $30 \%$ oor geen formele opleiding in rekeningkunde nie (kyk 4.4). Van hierdie groep kassiere het $80 \%$ aangetoon dat daar na hulle mening wel 'n behoefte bestaan aan so ' $n$ handleiding.

Daar is tans verskeie rekenaarpakkette op die mark beskikbaar wat spesifiek vir kerke ontwikkel is. Daar verskyn dan ook van tyd tot tyd in Die Kerkblad van die Gereformeerde Kerke advertensies oor sulke rekenaarpakkette. Dit is egter interessant dat 
nie een gemeente van so 'n pakket gebruik maak nie. Slegs $17 \%$ van die respondente het aangetoon dat die rekeningkundige werk van hul gemeentes gerekenariseer is. Hierdie respondente maak van algemene finansiële programme soos Lotus 123 gebruik.

Die finansiële jaarstate van $76 \%$ van die respondente word deur eksterne ouditeure geouditeer. Die respondente wie se finansiële jaarstate nie aan 'n eksterne oudit onderwerp word nie, het feitlik deurgaans aangevoer dat die finansiële toestand van hul gemeentes sodanig is dat hulle nie 'n eksterne oudit kan bekostig nie. Enkele van laasgenoemde groep respondente het egter aangedui dat 'n kundige lidmaat van die gemeente 'n oudit van die finansiële jaarstate onderneem.

Van die kassiere het $41 \%$ aangedui dat hulle gemeentes tans nie finansiële probleme ervaar nie, terwyl $53 \%$ aangedui het dat hulle gemeentes wel finansiële probleme ondervind en $6 \%$ dat hulle ernstige finansiële probleme ondervind. Van die respondente in die eerste groep hierbo (dié met geen finansiële probleme nie) het 'n hele paar egter aangedui dat hulle 'n kommerwekkende agteruitgang in hulle gemeentes se finansiële toestand bemerk wat, indien dit sou voortduur, sou kon meebring dat die gemeentes in die afsienbare toekoms wel finansiële probleme mag ondervind.

\subsection{Die kassier}

'n Onbeduidende persentasie van die kassiere ontvang enige vergoeding vir hulle diens. Die rede hiervoor is waarskynlik dat die kassier dikwels ook die amp van ouderling vervul en die kassierswerk as deel van die kerkraadsverantwoordelikhede beskou.

Die opleidingsvlak van kassiere in rekeningkunde is soos volg:

$\begin{array}{ll}\text { Dié met geen opleiding in rekeningkunde } & -30 \% \\ \text { Dié met matriekrekeningkunde } & -35 \% \\ \text { Dié met naskoolse opleiding in rekeningkunde } & -35 \%\end{array}$

Dit blyk dat die aantal ure wat kassiere aan kassierswerk bestee, wissel van 3 uur tot 50 uur per maand, met ' $n$ gemiddelde van 17 uur per maand. Kassiere wat ook die register van lidmaatbydraes moet byhou, bestee maandeliks aansienlik meer tyd aan die werk as kassiere in gemeentes waar die werk deur byvoorbeeld 'n administratiewe funksionaris verrig word.

Die berekening en administrering van belastingaftrekkings (bv. LBS, SIBW) is skynbaar nie 'n wesenlike probleem vir kassiere nie. Slegs $12 \%$ van die respondente 
het aangedui dat hulle wel probleme ondervind met die berekening en administrering van dié soort belasting.

Van die respondente het $35 \%$ aangedui dat hulle nie altyd op hoogte is van besluite van meerdere vergaderings (byvoorbeeld oor die aantal verpligte kollektes vir verskillende fondse) wat hulle werk as kassier raak nie. Dit is hoofsaaklik kassiere wat nie in die kerkraad dien nie wat hierdie probleem ondervind. 'n Wesenlike aantal van die kassiere wat aangedui het dat hulle wel ingelig is oor sulke besluite, moet egter dikwels self baie tyd afstaan om die handelinge van meerdere vergaderings na te gaan om vas te stel watter besluite hulle werk raak. Ses en sestig persent van die respondentkassiere het aangedui dat hulle 'n jaarlikse omsendbrief (opgestel deur byvoorbeeld die Administratiewe Buro van die Gereformeerde Kerk) waarin besluite van meerdere vergaderings wat op kassiere betrekking het uiteengesit word, sal verwelkom.

\section{GEVOLGTREKKING}

Die swak ekonomiese toestand in die land is besig om sy merk op die finansiële toestand van baie kerke te laat en byna $60 \%$ van die respondente het aangetoon dat hulle gemeentes finansiële probleme ondervind. Hierdie probleme gaan ook meebring dat finansiële beplanning en bestuur in die toekoms vir gemeentes van nog groter belang gaan word. Vir baie jare is daar feitlik geen navorsing gedoen oor die finansiële sake van die Gereformeerde Kerke nie en die presbiteriale kerkregeringstelsel in die Gereformeerde Kerke dra verder by tot die gebrek aan finansiële inligting. Uit hierdie navorsingspoging blyk dit duidelik dat daar 'n groot behoefte is aan navorsingsinligting wat vir gemeentes riglyne kan bied vir hul eie finansiële beplanning en bestuur. Weens die kerkregeringstelsel van die Gereformeerde Kerke sal dit waarskynlik nie moontlik wees vir 'n meerdere vergadering om sodanige riglyne op te stel nie. Uit die navorsing het dit geblyk dat hierdie behoefte eerder deur ' $n$ vrywillige en informele 'belangegroep', bestaande uit 'n paar kundige kassiere en predikante, bevredig kan word.

Daar word vertrou dat hierdie ondersoek 'n beskeie begin sal wees vir navorsing oor aspekte van die finansiële sake van die Gereformeerde Kerke. In hierdie geval was die doel veral die verkryging van die menings van predikante en kassiere van die kerk. Omdat soortgelyke navorsing nog nie voorheen onderneem is nie, was dit onmoontlik om die resultate van hierdie studie met vorige navorsingsresultate te vergelyk. Ook ander aspekte van die finansiële sake van die Gereformeerde Kerke bied 'n braakveld vir toekomstige navorsing, terwyl vergelykende studies tussen die sogenaamde susterkerke ook onderneem behoort te word. 
Die toekoms op ekonomiese gebied lyk donker en hierdie navorsing het derhalwe sekere probleme met betrekking tot aspekte van die finansiële sake van die Gereformeerde Kerke uitgewys. Genadiglik kry hierdie donker prentjie en probleme 'n ander kleur as daar in die geloof gekyk word na die Koning wat in beheer van die kerk is en na sy talle beloftes om die kerk te onderhou - ook op ekonomiese gebied.

\section{BIBLJOGRAFIE}

ARENS, A.A. \& LOEBBECKE, J.K. 1981. Applications of statistical sampling to auditing. Englewood Clifts : Prentice-Hall.

ARMACOST, R.L. \& SCHNEIDER, W.A. 1989. Financial management in church operation. CPA Jounal, LIX, (4):36-41

BOSHOFF, H. 1990. Die kerk in die negentigerjare. Potchefstroom : Instituut vir Toekomsstudies P.U. vir C.H.O.

BOYCE, LJ. 1984. Accounting for churches. Joumal of Accountancy, 157(2):96-102.

CUNNINGHAM, G.M. \& REEMSNYDER, D.E. 1983. Church accounting: the other side of stewardship. Management Accounting, 65:58-62.

DEPUTATE 1991. Dic almanak van die Gereformeerde Kerke in Suid-Afrika. Potchefstroom : Administraticwe Buro.

LUBBE, D.S. 1987. Ere-ouditeur moet pasop vir slaggate. Finansies en Tegniek, 39(16):34-36.

SPOELSTRA, B. 1989. Gereformeerde kerkreg en kerkregering. 'n Handboek by die kerkorde. Hammanskraal : Die Hammanskraalse Teologiese Skool van die Gereformeerde Kerke in SuidAfrika.

VAN DER WALT, J.J. 1972. Enkele opmerkings oor traktement. Die Griekwalander. Klassisblad Griekwaland-Wes.

DIE GEREFORMEERDE KERKE IN SUID-AFRIKA 1979. Kerkorde van die Gereformeerde Kerk in Suid-Afrika. Potchefstroom : Calvyn jubileum boekefonds.

KERKORDE 1979. 